\title{
0 desmonte do Estado brasileiro em um cenário de instabilidade e crise
}

Abrimos a apresentação deste número da RBPAE em um momento de crise política aguda no cenário nacional, marcado pelas grandes repercussões e desdobramentos do golpe de Estado levado a cabo em 2016, desencadeado em junho de 2013, com os grandes protestos nas ruas, que se intitulavam "apartidários" e apresentavam uma pauta difusa. A esse respeito, Chaú (2017) adverte que, quando um movimento assume a ideia de que "Meu partido é meu pás", está assumindo uma postura própria do nazismo, nascido na luta contra a socialdemocracia, sobretudo "quando o nazismo se opõe à República de Weimar e leva a pensar que os partidos políticos roubam ou tomam para si as ações políticas que caberiam exclusivamente ao governante" (CHAUÍ, 2017, p. 2). Ainda segundo a autora, nesse cenário, "o governante aparece como o chefe e é dele que deve emanar, transcendentemente, toda a decisão política. Desse ponto de vista, se os partidos políticos usurpam uma função que não é deles, é preciso eliminá-los" (Idem).

Sob o argumento do "combate à corrupção" e utilizando um discurso contra a "política" e os "políticos", os grandes meios de comunicação passaram a produzir e a acirrar a polarização entre os que queriam manter o governo eleito pelo voto, representado pela presidenta Dilma Rousseff, do Partido dos Trabalhadores, e aqueles que se mobilizaram para destituí-lo, representado pelo candidato derrotado nas eleições e presidente nacional do PSDB, o senador Aécio Neves, afastado do cargo em junho de 2017 após ser flagrado cometendo crimes de corrupção e obstrução da Justiça.

O movimento iniciado em 2013 e seus desdobramentos acabaram por contribuir para desabar a popularidade da presidenta Dilma Rousseff, e, embora ela tenha conseguido reeleger-se em 2014, seus oponentes, derrotados nas urnas, passaram a obstruir, no âmbito do Congresso Nacional, a maior parte das pautas propostas pelo seu governo. Esse cenário, aliado às repercussões, no Brasil, da crise econômica global, marcou a inversão da onda de otimismo que vivia o país até 2012. Nesse contexto, de acordo com Silva e Lima (2016), 
Alguns agentes políticos-econômicos-midiáticos visualizaram nas fendas abertas pelas manifestações orquestradas pela direita [que não aceitou a derrota nas urnas] uma oportunidade ímpar para fazer avançar seus intentos de assumir o controle sobre o poder político central. Lembremos que no final de 2014, mesmo com a vitória eleitoral (apertada) da presidente Dilma, a disputa não cessou. Assim, o pacto de se aceitar os resultados das urnas como forma de resolução dos grandes impasses políticos já não era mais suficiente para o apaziguamento político das forças contraditórias. A disputa deixa então a esfera eleitoral e adentra por caminhos imprevistos (p. 2).

Nesse contexto, mesmo adotando medidas econômicas impopulares que contrariavam seu Plano de Governo, os setores formados pelo empresariado e banqueiros não ficaram satisfeitos e passaram a propagar a tese de que o grande empecilho para a retomada do crescimento econômico do país era a presidenta Dilma Rousseff, sendo seu afastamento essencial para que o Brasil pudesse sair da crise.

Para agravar ainda mais o complexo quadro político, no dia 17 de março de 2014 foi deflagrada a "operação Lava Jato" pela Polícia Federal, que passou a protagonizar a cena político-policial nos grandes meios de comunicação. O objetivo inicial desta operação era investigar a ação ilegal de doleiros que praticavam crimes contra o sistema financeiro nacional. Entretanto, aos poucos as investigações foram se desdobrando e atingindo diversos políticos e empresários importantes na arena política e econômica nacional, levando à prisão alguns empresários, ex-governadores, ex-ministros e parlamentares.

Numa combinação de baixa popularidade da presidenta Dilma, falta de credibilidade política do legislativo e os desdobramentos da operação Lava Jato abriu-se o caminho para que o poder judiciário assumisse o protagonismo político e, aliado aos setores econômicos e midiáticos, passou a exercer o controle sobre o país. Exemplo de união de forças entre políticos da oposição ao governo, empresários financiadores de campanhas eleitorais e grande mídia foi a autorização do prosseguimento do pedido de impeachment da presidente Dilma Rousseff, em dezembro de 2015, pelo ex-presidente da Câmara dos Deputados, Eduardo Cunha, atualmente um dos presos da operação Lava Jato. No final de agosto de 2016, o Senado Federal aprovou a perda do mandato da presidenta Dilma, alegando que ela havia cometido crime de responsabilidade fiscal, assim como editado decretos de abertura de crédito ilegalmente, sem a autorização do Congresso.

O que causou grande estranheza nesse processo de impeachment é que o expediente usado pela presidenta Dilma foi recorrente em governos anteriores, à época considerada medida necessária à governabilidade. A posse do vicepresidente Michel Temer, do Partido do Movimento Democrático Brasileiro 
(PMDB), significou o rompimento da aliança entre o PMDB e o Partido dos Trabalhadores (PT), que fora importante para garantir a "governabilidade" do governo de Dilma Rousseff em seu primeiro mandato (2011-2014), bem como para possibilitar sua reeleição. Contraditoriamente o vice assumiu o governo sobre a sustentação da base política derrotada nas eleições de 2014, ou seja, dos políticos "expoentes" do PSDB e partidos aliados. Esse arranjo mostrou com muita clareza a natureza "golpista" do processo de impeachment, levando ao Planalto um projeto de governo que havia sido derrotado nas urnas, baseado na retirada de investimentos públicos em políticas sociais.

Para Chauí(2017), esse movimento contrário à social democracia e que contesta o papel do Estado no equilíbrio de forças entre o capital e o trabalho emergiu porque apesar

Dos percalços éticos, políticos e econômicos das duas últimas décadas, o país tenta entrar na Modernidade, que exige necessariamente inclusão social. Essa mesma inclusão, no entanto, desperta resistência. Se os auxílios financeiros para inserção econômica, distribuídos por países como Alemanha e França às populações mais pobres, são considerados por lá sinais de desenvolvimento, o Bolsa Família, no Brasil, é chamado de assistencialismo e de estratégia eleitoreira. Se a ação do Estado no controle do mercado é vista como necessária em outras partes do mundo, aqui ela é chamada de "ameaça comunista" e de inchaço da máquina pública (p. 3).

Essa tese de Chauí pode ser comprovada ao se observarem as medidas adotadas pelo novo governo, alinhado aos princípios econômicos do Estado mínimo para as políticas sociais e máximo para o capital, representado pelos grandes empresários da indústria, do agronegócio e dos meios de comunicação. A esse respeito Chauí afirma que

\footnotetext{
A situação é gravíssima, não por causa daquilo que a mídia apresenta como sendo a falência do governo, mas pelo movimento conservador reacionário, de extrema direita e protofascista que está tomando conta da pauta política. Quando examinamos os pontos da pauta política discutidos de outubro de 2015 até agora, vemos o poder dos grupos dos "3B": o boi, a bala e a Bíblia (Idem, p.5).
}

Para a autora, trata-se de uma verdadeira regressão sociopolítica, apresentando uma pauta regressiva, antidemocrática, de violação de todos os direitos conquistados ao longo dos últimos quinze anos; afirma que

O fundo reacionário protofascista que existe no Brasil e que é alimentado pela classe média urbana brasileira veio à tona e pegou as esquerdas completamente desprevenidas. As esquerdas tinham pautas como o antineoliberalismo, voltadas aos problemas da democracia e do socialismo, e foi pega completamente despreparada por uma onda de extrema direita que repôs para o Brasil os tópicos que estiveram 
em vigência no início dos anos 1960. É um golpe para reverter o processo de consolidação dos direitos sociais obtidos nos últimos anos e sustentada pela pauta "boi, bala e Bíblia". Aliás, a atuação de grupos religiosos é muito preocupante e vai além de uma questão propriamente política, porque, apesar de se manifestar na representação política, ela é uma questão socioeconômica: é a maneira como as igrejas evangélicas interiorizaram e reformularam a concepção neoliberal (idem, p.7).

Essa guinada à direita pode ser nitidamente observada pelo grande destaque dado às pautas que visam a desfazer no Congresso toda uma trajetória de valorização dos movimentos sociais e das entidades que representam as minorias sociais, grupos historicamente excluídos como indígenas, quilombolas, LGBT'TT' ${ }^{1}$, coletivo de mulheres, trabalhadores do campo, $\mathrm{MST}^{2}$, etc. Além disso erigiu-se também uma verdadeira batalha no Congresso Nacional pela retirada dos direitos sociais, inicialmente com a aprovação da EC 95, de 16 de dezembro de 2016, que congela as despesas primárias do Poder Executivo e libera o pagamento de juros, encargos e amortizações da dívida pública, bem como seus desdobramentos, que atualmente tramitam a passos rápidos: a Reforma Trabalhista e a Reforma da Previdência.

Em meio a um cenário repleto de incertezas e pressões sociais pelas "Diretas Já" como solução política que reorganize as instituições brasileiras, mais um escândalo de grandes proporções causa tumulto no Palácio do Planalto: por meio de um acordo de delação premiada, executivos de uma grande empresa envolvidos no esquema de propinas a parlamentares e financiadores de campanhas eleitorais entregaram gravações de áudios que comprovam o envolvimento do presidente da república em esquemas criminosos. Além de incriminar o presidente Michel Temer, a delação também envolveu o senador Aécio Neves, até então presidente do PSDB, que, após a divulgação do material pela mídia, perdeu o comando do seu partido e foi afastado pela Justiça das suas funções de senador. Ambos são acusados pela Justiça de terem sido coniventes com a corrupção e de obstruir a justiça.

Segundo Silva e Lima (2016), "diante deste cenário de crise aguda das instituições políticas, parte das elites políticas, econômicas e midiáticas se esforçam para encontrar alguma saída para a crise" (p. 3). Neste momento, junho de 2017, há um esforço por parte de vários setores da mídia e da sociedade civil organizada pela saída de Temer, que poderia dar-se por meio de uma das três principais possibilidades: a renúncia (à qual ele já se manifestou contrário, inclusive por implicar perda do foro privilegiado, o que poderia levá-lo à prisão pelo crime de obstrução de justiça); a cassação pela Justiça da chapa Dilma-Temer

1 Sigla do movimento de Lésbicas, Gays, Bissexuais, Travestis, Transexuais e Transgêneros

2 Movimento dos Sem Terra.

278 - RBPAE - v. 33 , n. 2, p. 275 - 284, mai./ago. 2017 
pelo Supremo Tribunal Eleitoral, a pedido do PSDB, acusando a referida chapa de abuso de poder político e econômico para se reeleger (em julgamento ocorrido em junho de 2017 o STE, por 4 votos a 3, considerou improcedente a acusação). E, por fim, a terceira possibilidade seria um processo de impeachment, como o já encaminhado à Câmara dos Deputados pela Ordem dos Advogados do Brasil. Nesse caso, o presidente da Câmara teria que acolher o pedido e colocá-lo em pauta para apreciação e votação, algo pouco provável considerando que são os mesmos parlamentares que votaram pelo afastamento da presidenta Dilma em um grande acordo para empossar o vice e colocar em curso a agenda de reformas.

Insistindo em permanecer na presidência, mesmo sendo investigado por crimes comprovados e amargando uma impopularidade histórica, Temer se transformou num verdadeiro "cadáver político". Em caso de vacância no cargo, a Constituição Federal prevê uma eleição indireta para um mandato tampão até que se façam novas eleições, previstas para o fim de 2018. Entretanto, com tantos políticos envolvidos com esquemas de corrupção, cresce e ganha força o movimento pelas "eleições diretas já", como única forma de retomar o processo democrático e devolver a normalidade política e institucional ao Estado brasileiro.

Enquanto isso, o governo Temer segue atuando contra a democracia e promovendo retrocessos políticos próprios de estado de exceção, como, por exemplo, a publicação de um decreto autorizando o uso das Forças Armadas no Distrito Federal, em nome da defesa da ordem, entre os dias 24 e 31 de maio, após a capital ter se tornado palco de uma histórica manifestação popular pedindo sua saída, contra as reformas trabalhista e da previdência e contra o corte dos gastos públicos na área social.

A esse respeito, mais uma vez recorremos a Chauí (2017), que propõe como "chave de leitura" do Brasil a ideia de que a sociedade brasileira é autoritária e violenta. Em sua obra Cultura e Democracia: o discurso competente e outras falas, a autora

\footnotetext{
Contraria a imagem de uma cultura nacional pretensamente formada pelo acolhimento recíproco e pela cordialidade, revelando estruturas enraizadas de hierarquização e de sedução pela autoridade. Não se trata, porém, de considerar os brasileiros como individualmente violentos. Trata-se de esclarecer as estruturas históricas que produzem uma vida social em que o espaço público e republicano é minguado, transferindo-se ao Estado o papel de sujeito da cidadania e reproduzindose, no cotidiano, relações de poder $(2017$, p. 8).
}

Podemos afirmar que essa chave de leitura permanece extremamente atual para analisar o momento vivido pelo Brasil. Apesar dos percalços éticos, políticos e econômicos das duas últimas décadas, o Brasil vinha tentando entrar 
na Modernidade por meio da inclusão social, pauta que, após o golpe de Estado de 2016, deu lugar ao desmonte das políticas sociais em nome dos ajustes exigidos pelo "mercado" e seus porta-vozes jurídicos, midiáticos e parlamentares.

Diante deste cenário, a Rbpae e a Anpae engrossam as fileiras das entidades educacionais que apoiam o restabelecimento da democracia, e lutam por ela, por meio da convocação de eleições gerais, única saída para a grave crise política e econômica que agride de maneira inconteste a vida dos brasileiros. Além disso, somente com o restabelecimento do Estado democrático será possível restabelecer também as políticas educacionais propostas no Plano Nacional de Educação, o PNE 2014-2024, construído a partir da mobilização do Fórum Nacional de Educação (FNE) nas Conferências Nacionais de Educação (Conaes 2010 e 2014), duramente esvaziados com as medidas de congelamento dos recursos destinados ao Poder Executivo por 20 anos e desmonte do FNE pelo atual ministro da Educação.

É nesse cenário de incertezas no campo das políticas educacionais que passamos a apresentar os artigos que compõem este número da revista, certas de que a produção e a divulgação dos conhecimentos produzidos nas universidades são instrumentos fundamentais na luta constante em defesa da educação pública e de qualidade socialmente referenciada. Esperamos lograr êxito no árduo campo de batalhas em defesa do ensino público em todos os níveis e modalidades, ao tempo em que, no atual governo, só se conjugam os verbos "privatizar", "terceirizar" e "enxugar".

O artigo que abre esta coletânea é escrito por Jefferson Mainardes, Silvana Stremel e Gregory Luis Rolim Rosa, intitulado A pesquisa sobre a disciplina política educacional no Brasil: situação e perspectivas, que têm como objetivo analisar a situação da pesquisa sobre a disciplina Política Educacional no Brasil nos Cursos de Pedagogia e outras Licenciaturas. Realizada no âmbito da Red de Estudios Teóricos y Epistemológicos en Política Educativa, a ReLePe, cujo foco é ampliar as discussões de natureza teórico-epistemológica da pesquisa em política educacional, partiu da constatação de que se trata de um campo abrangente, recente, em expansão e em construção, com diversas questões teórico-metodológicas e epistemológicas a serem aprofundadas, especialmente no contexto da América Latina. O artigo apresenta um breve histórico da disciplina no contexto da emergência e desenvolvimento da política educacional como campo acadêmico no Brasil, seguido de uma síntese dos trabalhos de pesquisa sobre o tema. Por fim, concluem os autores que há diversos aspectos a serem explorados nesse campo, sobretudo os aspectos históricos da disciplina nos cursos de formação de professores, política educacional e realidade latino-americana; ensino de política educacional e a formação de pesquisadores para esse campo. 
$\mathrm{O}$ artigo seguinte, intitulado Hierarquias democráticas e direito à aprendizagem corporativa, de autoria de André Antunes Martins, apresenta um estudo das composições de força como constituidoras da(s) realidade(s), valendo-nos dos argumentos deleuzianos. Considera as possibilidades de insubmissão das hierarquias democráticas (linhas/força ativa) e do controle/centralização das hierarquias gerenciais (pontos/força reativa), sobretudo, no que tange às propostas de gestão e aprendizagem das corporações financeiras. O autor elege como questão principal a perspectiva de que não se trata de superação de hierarquias, como comumente poderíamos supor, mas de provocar outras formas organizativas.

O próximo artigo, escrito por Rita de Cássia Cândido e João Augusto Gentilini intitula-se Base Curricular Nacional: Reflexões sobre autonomia escolar e o Projeto Político-Pedagógico trata de um tema atual e relevante para a educação brasileira, que é a Base Nacional Curricular Comum (BNCC). Destacam que este documento consiste em objeto de muitas disputas no que tange à autonomia escolar na construção do Projeto Pedagógico. Por meio de uma pesquisa bibliográfica, os autores questionam as pretensões da BNCC na definição dos currículos e alertam para o perigo de uma "superlotação no tempo escolar, onde os professores e direção tenham que correr o tempo todo atrás de uma demanda, obrigatória, esquecendo-se daquilo que é próprio da realidade local".

O quarto artigo intitulado O Plano de Ações Articuladas e o regime de colaboração: promessas não cumpridas de fortalecimento das relações de colaboração entre os municípios e a união, escrito por Luís Gustavo Alexandre da Silva analisa as limitações do Plano de Ações Articuladas (PAR) no cumprimento do propósito de fortalecer as relações de colaboração entre os municípios e a união. A pesquisa utiliza como metodologia a aplicação de questionários e a realização de entrevistas semiestruturadas. $\mathrm{O}$ autor conclui que, ao priorizar a racionalidade técnica como elemento articulador do projeto educativo, o PAR não consegue operacionalizar seus objetivos a contento porque não possui as condições estruturais e políticas para se efetivar. Situação que expõe a ausência de um amplo e consistente acordo político na sociedade brasileira, referente à perspectiva de educação, de sociedade e de planejamento que deve sustentar a organização do sistema educacional brasileiro. Os resultados mostram também os limites dessa proposição em razão do grau de precariedade dos sistemas municipais de educação e da perspectiva de planejamento submetida aos princípios da descentralização e dos parâmetros da nova gestão pública.

O texto que segue, escrito por Alexandre José Rossi, Liane Maria Bernardi e Lucia Hugo Uczak, intitulado Relações entre Estado e empresários no PDE/PAR: algumas contradições na política educacional brasileira, também aborda a política 
de planos e apresenta discussões sobre como o setor privado mercantil influencia as políticas educacionais brasileiras e expõem as relações do Movimento Todos pela Educação com as políticas públicas educacionais. Os autores mostram as influências da classe empresarial na criação de políticas no setor público ao mesmo tempo em que também é cliente do Estado, ofertando tecnologias educacionais. Nesse contexto, o Estado se articula em torno de consensos de propostas educacionais junto ao governo federal, naturalizando a incorporação da associação entre o público e o privado.

$O$ artigo que vem a seguir, intitulado Relações colaborativas entre a União e as municipalidades: faces de uma política em ação, escrito por Cleciana Alves de Arruda e Ana Lúcia Félix dos Santos, apresenta resultados de uma pesquisa que analisou os limites e as possibilidades para a materialização do regime de colaboração entre municípios do Agreste de Pernambuco e a União, a partir da implementação do Plano de Ações Articuladas (PAR). O estudo amparou-se na avaliação de políticas públicas e os dados foram coletados em documentos e entrevistas realizadas com sujeitos envolvidos na implementação do PAR. As autoras concluíram que a colaboração analisada refletiu a indução de ações pela União, mas também apresentou indícios de contribuição para fortalecimento da autonomia e da gestão educacional local.

O próximo artigo é de autoria de Daniel Cabral de Almeida, Victor Hugo Lessa Pierre, Carlos Eugênio Silva da Costa, Luciana Peixoto Santa Rita e Ibsen Mateus Bittencourt Santana Pinto e intitula-se ENEM: Uma análise do efeito das políticas públicas educacionais em Alagoas e a comparação do resultado do ranking com os demais estados do Nordeste e analisa os resultados de Alagoas no ranking do Exame Nacional do Ensino Médio entre 2013 e 2015, comparando-os com os demais estados do Nordeste. Por meio de uma abordagem de pesquisa quali-quantitativa, o trabalho identificou as especificidades que contribuem para a conquista das melhores notas e a aplicação das políticas públicas educacionais em Alagoas. O estudo revelou que as escolas da Bahia e de Pernambuco detêm os melhores resultados do Nordeste e que o nível socioeconômico tem grande influência nos resultados das escolas. Observou-se ainda que o indicador de formação docente não é determinante chave na elevação das notas no exame e que o ranking é inapropriado para indicar aos pais a qualidade da escola.

A seguir apresentamos o artigo intitulado Politicas de inclusão escolar: um estudo sobre a classe hospitalar no Brasil, de autoria de Ricardo Antônio Gonçalves Teixeira, Uyara Soares Cavalcanti Teixeira, Mário José de Souza e Pedro Paulo Pereira Ramos. O estudo tem como tema a classe hospitalar, uma modalidade de ensino decorrente da educação especial na perspectiva de inclusão escolar. Apresenta um quadro teórico, metodológico e documental das produções 
científicas sobre classes hospitalares no Brasil e se caracteriza como estudo bibliográfico valendo-se do método de Revisão Sistemática. Como resultados, apresenta a predominância da pesquisa qualitativa como metodologia de estudo; a proveniência de publicações vinculadas a instituições federais de ensino; recorrência de estudos focados em atividades de formação docente e sondagem sobre percepção de acompanhantes a respeito de atendimentos pedagógicos realizados no âmbito hospitalar. Contribui com uma matriz de referência teóricodocumental, servindo de base para estudos sobre o tema.

$\mathrm{O}$ artigo intitulado Análise de política como metodologia em estudo do transporte escolar rural, escrito por Calinca Jordania Pergher e Nalú Farenzena apresenta os resultados de uma pesquisa sobre a política do transporte escolar rural no Rio Grande do Sul, na qual são explicitadas diversas noções, conceitos e abordagens, com ênfase na abordagem cognitiva, de linha francesa, e na análise sequencial de políticas, suas características e o modo como foram combinadas na pesquisa. São narradas rotas percorridas na reconstrução analítica da política, nas fases de emergência do problema, colocação na agenda, formulação e adoção do programa e implementação. As autoras concluem que dentre as políticas públicas educacionais que visam a garantir acesso, permanência e sucesso/qualidade, o transporte escolar rural tem especial destaque como um dos meios para que muitos brasileiros tenham garantido seu direito à educação.

Encerrando este número apresentamos o artigo escrito por José da Silva Santos Junior e Giselle Cristina Martins Real intitulado $O$ acesso à Educação Superior na Universidade Federal da Grande Dourados: Trajetória de Estudantes Ingressantes entre 2006-2009. O estudo objetivou analisar os índices de evasão, de permanência prolongada e de conclusão de curso de graduação na Universidade Federal da Grande Dourados, buscando relacionar os dados quantitativos aos fenômenos da trajetória acadêmica em períodos de expansão da Educação Superior. A metodologia utilizada é de acompanhamento de coorte, interpretando-se os dados por meio de estatística descritiva. Os resultados mostraram um aumento real na retenção de estudantes ingressantes entre 2006 e 2009 na instituição, bem como uma diminuição dos percentuais de concluintes ao longo dos anos.

Desejamos a todos uma ótima leitura. 


\section{REFERÊNCIAS}

CHAUÍ, Marilena, Entrevista a. Sociedade brasileira: violência e autoritarismo por todos os lados. In: FILHO, Juvenal Savian e MODELLI, Laís. REVISTA CULT, Edição 209. Disponível em: <https://limpinhoecheiroso.com/2016/02/23/ marilena-chaui-brasil-atual-fara-1964-parecer-simples/>. Acesso em 16/06/2017.

SILVA, José Medeiros; LIMA, Rafael Gonçalves. Para se entender a crise política do Brasil. DIÁRIO DO POVO. Disponível em: <http:/ /www.vermelho.org.br/ noticia/297359-1>. Acesso em: 17/06/2017.

Lúcia Maria de Assis

Editora

Daniela da Costa Britto Pereira Lima

Editora Associada 